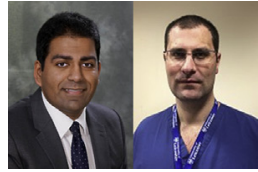

\section{WHEN DIAMETER IS NOT ENOUGH: IN SEARCH OF THE IDEAL PATIENT-SPECIFIC SIZE PARAMETER FOR AORTIC RISK PREDICTION}

\section{To the Editor:}

Despite current guidelines generally recommending elective isolated ascending aortic replacement at a diameter of 5.0 to $5.5 \mathrm{~cm}$, absolute diameter may be a somewhat inadequate guide to prophylactic aortic repair. The relative risk of dissection is statistically very low among the vast numbers of mild to moderately enlarged aortas compared with that of less-prevalent larger aneurysms (the aortic paradox); however, diameter fails to account for age, sex, and body habitus, which significantly influence aortic size.

As highlighted by Girardi and colleagues ${ }^{1}$ in this issue of the Journal, several alternative parameters characterizing aortic dimension have been proposed to predict aortic adverse events (AAEs). Extended ascending aortic length $\geq 13 \mathrm{~cm}$ corresponds to an almost fivefold greater annual risk of AAEs, ${ }^{1}$ and $\geq 11 \mathrm{~cm}$ is suggested for aneurysm resection. As a surrogate for aortic length, a value $>1.95$ for the aortic tortuosity index, calculated as the ratio of centerline and linear aortic distances, implies a 13-fold greater dissection risk. ${ }^{1}$ Sophisticated aortic volumetry techniques permit detection of even subtle aortic growth. None of these aforementioned metrics is referenced in aortic guidelines, however.

So what constitutes an ideal aortic size-based parameter for AAE prediction? Such a variable should be patient-specific, straightforward to calculate without complex statistics, reflect sound physiological principles, and accurately identify at-risk aneurysms.

Indexing aortic dimensions has emerged to individualize aortic risk stratification. Elefteriades' group devised an Aortic Size Index, ${ }^{2}$ calculated as aortic diameter/body surface area, as a better predictor of AAEs than isolated diameter, recommending surgical intervention above a $2.75 \mathrm{~cm} / \mathrm{m}^{2}$ cutoff. Incorporating body surface arear calculations into risk assessment may be cumbersome and unreliable, however, given that weight is subject to

\footnotetext{
The Editor welcomes submissions for possible publication in the Letters to the Editor section that consist of commentary on an article published in the Journal or other relevant issues. Authors should: $\bullet$ Include no more than 500 words of text, three authors, and five references. • Type with double-spacing. • See http://jtcs.ctsnetjournals.org/ misc/ifora.shtml for detailed submission instructions. • Submit the letter electronically via jtcvs.editorialmanager.com. Letters commenting on an article published in the JTCVS will be considered if they are received within 6 weeks of the time the article was published. Authors of the article being commented on will be given an opportunity of offer a timely response ( 2 weeks) to the letter. Authors of letters will be notified that the letter has been received. Unpublished letters cannot be returned.
}

substantial fluctuation. Elefteriades' group later developed a simpler Aortic Height Index ${ }^{3}$ to determine AAE risk as a function of both aortic diameter and patient height.

Perhaps integrating aortic area into risk estimation would better reflect the hemodynamic forces exerted across the aortic wall? Cross-sectional aortic area/patient height ratio $>10 \mathrm{~cm}^{2} / \mathrm{m}$ was first proposed as an indicator of AAEs by Svensson and colleagues in 2002. ${ }^{4}$ Our group has shown that almost $70 \%$ of susceptible proximal aortic aneurysms identified using this parameter would not satisfy the size criteria for preventative surgery owing to their subthreshold diameters. ${ }^{5}$ Furthermore, indexed aortic area has received only limited endorsement in guidelines as a reasonable indication for surgical repair in inherited aortopathies.

These efforts to define the ideal patient-specific size parameter to predict AAEs should emphasize the importance of carefully assessing patients' individual risk profiles according to their personal characteristics, rather than generalizing across broader aortic populations, to offer them elective aneurysm surgery at the most appropriate interval.

We have adopted the cross-sectional aortic area/patient height ratio, a diameter-based index, in borderline cases of moderately dilated aortas to facilitate their assignment to a higher-risk category and thus better inform surgical decision making. The $\pi r^{2}$ formula suffices for area calculation assuming a circular ascending aortic contour, or, alternatively, planimetry can be used evaluate more irregular aortic areas. We believe that this is an uncomplicated, reproducible method for identifying at-risk aneurysms, although further work is needed to accurately quantify these predicted risks.

$$
\begin{array}{r}
\text { Metesh Acharya, MRCS } S^{a, b} \\
\text { Giovanni Mariscalco, MD, PhD }{ }^{a} \\
\text { Marjan Jahangiri, FRCS }(C T h)^{b} \\
{ }^{a} \text { Department of Cardiac Surgery } \\
\text { Glenfield Hospital } \\
\text { Leicester } \\
{ }^{b} \text { Department of Cardiothoracic Surgery } \\
\text { St. George's Hospital } \\
\text { London, United Kingdom }
\end{array}
$$

\section{References}

1. Girardi LN, Lau C, Gambardella I. Aortic dimensions as predictors of adverse events. J Thorac Cardiovasc Surg. 2021;161:1193-7.

2. Davies RR, Gallo A, Coady MA, Tellides G, Botta DM, Burke B, et al. Novel measurement of relative aortic size predicts rupture of thoracic aortic aneurysms. Ann Thorac Surg. 2006;81:169-77.

3. Zafar MA, Li Y, Rizzo JA, Charilaou P, Saeyeldin A, Velasquez CA, et al. Heigh alone, rather than body surface area, suffices for risk estimation in ascending aortic aneurysm. J Thorac Cardiovasc Surg. 2018;155:1938-50.

4. Svensson LG, Khitin L. Aortic cross-sectional area/height ratio and timing of aortic surgery in asymptomatic patients with Marfan syndrome. J Thorac Cardiovasc Surg. 2002;123:360-1. 
The authors reported no conflicts of interest.

The Journal policy requires editors and reviewers to disclose conflicts of interest and to decline handling or reviewing manuscripts for which they may have a conflict of interest. The editors and reviewers of this article have no conflicts of interest.

5. Acharya MN, Youssefi P, Soppa G, Valencia O, Nowell J, Kanagasabay R, et al. Analysis of aortic area/height ratio in patients with thoracic aortic aneurysm and type A dissection. Eur J Cardiothorac Surg. 2018;54:696-701.

https://doi.org/10.1016/j.jtcvs.2020.09.041

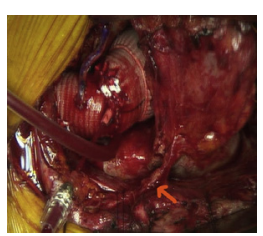

REPLY: THE FUTURE OF GUIDELINE-BASED PROPHYLACTIC PROXIMAL AORTIC SURGERY IS "PATIENT-SPECIFIC" BUT NOT DIAMETER-

\section{Reply to the Editor:}

In the current issue of the Journal, Acharya and colleagues ${ }^{1}$ detail in a letter to the editor their recommendations regarding the use of "patient-specific" size parameters for aortic risk prediction and prophylactic proximal aortic surgery. They suggest that the ratio of cross-sectional aortic area/patient height is a reproducible method for identifying at-risk aneurysms and may better inform surgical decision-making. Although the authors are to be commended for their work in this area, given the clearly inadequate current aortic dimensions-based guidelines (Figure 1), which are comprehensively detailed in a recent review in the Journal, ${ }^{2}$ the ratio espoused by the authors remains a diameter-based index, and we know that any parameter that relies on aortic dimensions suboptimally predicts patient-specific dissection risk.

Recent work from Maiti and colleagues ${ }^{4}$ from the University of Pittsburgh using a fiber-level finite elementbased structural model of the aortic wall found that the organization and failure properties of the collagen fibers are the primary determinants of aortic tissue strength. Further, they suggested a biomechanically based paradigm

\section{BASED METRICS}


FIGURE 1. CTA and operative images from a 60-year-old male patient status-post previous coronary artery bypass grafting (including bilateral pedicled IMA grafts) 10 years earlier, who dissected under aortic surveillance with aortic dimensions not meeting criteria for surgical intervention. A, Routine surveillance 3D reconstruction CTA image done 2 months before the patient presented with an acute type A dissection. B, Coronal reconstruction image from same scan demonstrating 4.7-cm maximal aortic root diameter, which was stable from the previous year's imaging and did not meet criteria for surgical intervention. C, 3D reconstruction image done 2 months later when the patient presented with an acute type A dissection. D, Coronal reconstruction image from same scan demonstrating increase in maximal aortic root diameter to $5.1 \mathrm{~cm}$ as a consequence of the dissection. E, Intraoperative photograph of completed bio-Bentall and hemiarch repair with saphenous vein graft extension to his previous radial arterial graft. Both pedicled IMA grafts were preserved (arrow indicates pedicled RIMA graft). F, Surveillance CTA 6 years postoperatively at which time the patient continues to do well clinically. RIMA, Right internal mammary artery; LIMA, left internal mammary artery. 